Original article

\title{
How healthcare workers are coping with mental health challenges during COVID-19 pandemic? - A cross-sectional multi-countries study
}

\author{
Mila Nu Nu Htay a, , Roy Rillera Marzo ${ }^{\mathrm{b}, \mathrm{c}}$, Rafidah Bahari ${ }^{\mathrm{d}}$, Ayesha AlRifai ${ }^{\mathrm{e}}$, Fatjona Kamberi ${ }^{\mathrm{f}}$, \\ Radwa Abdullah El-Abasiri $^{g}$, Jeldah Mokeira Nyamache ${ }^{\mathrm{h}, \mathrm{i}, \mathrm{j}, \mathrm{k}, 1, \mathrm{~m}}$, Htet Aung Hlaing ${ }^{\mathrm{n}}$, \\ Mayada Hassanein ${ }^{\circ}$, Soe Moe ${ }^{a}$, Adinegara Lutfi Abas ${ }^{a}$, Tin Tin $\mathrm{Su}^{\mathrm{p}}$ \\ ${ }^{a}$ Department of Community Medicine, Melaka-Manipal Medical College, Manipal Academy of Higher Education (MAHE), Melaka, Malaysia \\ ${ }^{\mathrm{b}}$ Department of Public Health, Faculty of Medicine, Asia Metropolitan University, Johor, Malaysia \\ ${ }^{\mathrm{c}}$ Department of Community Medicine, International Medical School, Management and Science University, Selangor, Malaysia \\ ${ }^{\mathrm{d}}$ Department of Psychiatry, Faculty of Medicine, University of Cyberjaya, Cyberjaya, Malaysia \\ e Birzeit University \& Arab American University in Palestine, Palestine \\ ${ }^{\mathrm{f}}$ Research Centre of Public Health, Faculty of Health, University of Vlore "Ismail Qemali", Vlore, Albania \\ ${ }^{g}$ Department of Pharmacy Practice and Clinical Pharmacy, Faculty of Pharmaceutical Sciences and Pharmaceutical Industries, Future University in Egypt, Cairo, Egypt \\ ${ }^{\mathrm{h}}$ North Star Alliance, Kenya \\ ${ }^{\mathrm{i}}$ North Star Alliance, Uganda \\ ${ }^{\mathrm{j}}$ North Star Alliance, Tanzania \\ ${ }^{\mathrm{k}}$ North Star Alliance, Zimbabwe \\ ${ }^{1}$ North Star Alliance, Mozambique \\ ${ }^{\mathrm{m}}$ North Star Alliance, South Africa \\ ${ }^{\mathrm{n}}$ Senior Resident Medical Officer (General Practitioner), Pun Hlaing Siloam Hospital, Yangon, Myanmar \\ ${ }^{\circ}$ Maternal and Child Health Unit, Alexandria Fever Hospital, Alexandria, Egypt \\ ${ }^{\mathrm{p}}$ South East Asia Community Observatory (SEACO) \& Global Public Health, Jeffery Cheah School of Medicine and Health Sciences, Monash University Malaysia, Bandar Sumway, Malaysia
}

\section{A R T I C L E I N F O}

\section{Keywords:}

COVID-19

Coronavirus

Mental health

Adaptation

Psychological

Interprofessional relations

\begin{abstract}
A B S T R A C T
Background: The coronavirus pandemic (COVID-19) has a social and psychological impact among healthcare workers worldwide and appropriate coping strategies are essential to avoid the negative mental health effects. This study aimed to investigate the coping strategies among the healthcare workers from different countries and their attitude towards teamwork during the COVID-19 pandemic.

Methods: A cross-sectional study was conducted by using an online, web-based questionnaire, which was distributed to healthcare workers from 32 countries during April and May 2020. The respondents were recruited by the non-random convenience sampling method.

Results: A total of 2166 respondents responded to the survey and the majority were working in low- and middleincome countries. Among them, 36\% were doctors, 24\% were nurses and 40\% worked in other healthcare sectors. More than $70 \%$ of the respondents answered that "getting family support" and "positive thinking" were coping methods for them during the COVID-19 pandemic. Approximately half of the respondents worshiped according to their belief and conducted prayers (58.4\%) and had adequate sleep and food intake (48.2\%). The significant associations were observed between attitude score towards interprofessional teamwork and gender $(\mathrm{p}=0.009)$, age $(31-45$ years $)(\mathrm{p}<0.001)$, marital status $(\mathrm{p}<0.001)$, occupation $(\mathrm{p}<0.001)$, working experience ( $2-5$ years) ( $\mathrm{p}=0.005)$, current workplace (clinics) $(\mathrm{p}=0.002)$.

Conclusion: The local healthcare authorities should promote coping methods and develop an innovative way to encourage practicing among healthcare workers. Digital mental health support interventions or workplace mental health support teams should be accessible to protect mental wellbeing among healthcare workers.
\end{abstract}

\footnotetext{
* Corresponding author.

E-mail addresses: drmlnnh@gmail.com (M.N.N. Htay),rrmtexas@yahoo.com (R.R. Marzo), rafidahbahari@cyberjaya.edu.my (R. Bahari), a.alrifai1@gmail.com

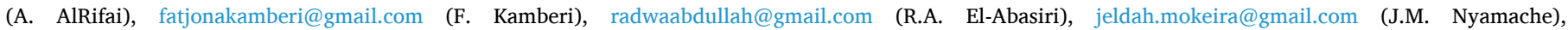

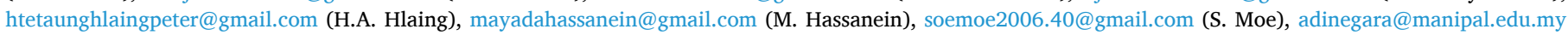
(A.L. Abas), TinTin.Su@monash.edu (T.T. Su).
}

https://doi.org/10.1016/j.cegh.2021.100759

Received 11 February 2021; Received in revised form 13 April 2021; Accepted 22 April 2021

Available online 7 May 2021

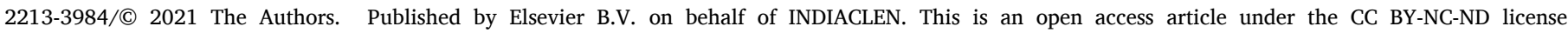




\section{Introduction}

The coronavirus pandemic (COVID-19) has an impact on the social and psychological impact on the general populations ${ }^{1}$ as well as the healthcare workers. ${ }^{2}$ Among the healthcare workers, fear of contagion, transmitting infection to their families' members, inadequate protective measures, and risk of medical violence imposed the burden on their mental health. ${ }^{2,3}$ Lockdown measures caused the psycho-social impact and it was significantly associated with gender, occupation, and physical activities among the respondents in India. ${ }^{4}$ The evidence has been reported the sufferings of psychological distress, insomnia, anxiety, and depression among the healthcare providers. ${ }^{2,5,6}$ The systematic reviews on the mental health impact due to COVID-19 reported that the estimated prevalence of insomnia among the healthcare workers are $38.9 \%,{ }^{7} 27.4-71.5 \%$ suffered stress, the prevalence of anxiety and depression are from 23.04 to $44.6 \%$ and $8-50.4 \%$ respectively. 8,9 Frontline healthcare workers, female, nurses, stationed in Wuhan ${ }^{2,5}$ were reported to have a higher psychological burden. Therefore, timely mental health care, support, and coping strategies are in urgent need for the healthcare workers amidst of pandemic. ${ }^{3}$ The economic condition had shown an impact on health in 26 European countries after the 2008 economic recession, ${ }^{10}$ however, the study was conducted among the general population. In our study, we focus on healthcare workers and coping strategies, and therefore, we have excluded the socio-economic consideration.

Informing the update on the pandemic, clear communication, arrangement on appropriate shift hours, training on the management of COVID-19 patients, prevention measures, and providing guides for the appropriate usage of protective equipment could be beneficial for the healthcare workers. ${ }^{7}$ The World Health Organization advised the healthcare workers for self-care particularly for maintaining healthy lifestyles and getting informal social support. The recommendation included adequate sleep and rest, eating a healthy and sufficient diet, maintaining physical activities, and stay in touch and get support from family and friends. On a contrary, de-stressing by using alcohol, tobacco, and other drugs were strongly discouraged since they might impose complications to the long-term wellbeing of the healthcare workers. ${ }^{11}$ Therefore, it is crucial to understand the coping strategies among healthcare workers across the globe to inform the local healthcare managers and policymakers to prepare for the supportive interventions.
During the previous Ebola epidemics, the healthcare workers revealed that training, workshops, and supply of PPE, and essential resources improved to overcome fear and gain confidence in patient management. ${ }^{12} \mathrm{~A}$ recent qualitative study with 15 male healthcare workers in Pakistan revealed that limited spending the time on the news, media and limiting the sharing of detailed info about the COVID-19 management duties could help them to reduce stress and vulnerability. ${ }^{13}$ Religious coping strategy played an integral role in coping with stress among those front-line healthcare workers. ${ }^{13}$ Positive perception of their roles during the pandemic as another emergency situation and providing care with empathy could help to manage their mental health challenges. ${ }^{13}$

Multidisciplinary teamwork is essential in the healthcare sector and had proven benefits on the patients' outcome. ${ }^{14}$ Moreover, a positive attitude towards teamwork and having good team support could reduce burnout, improve job satisfaction and create a healthy working environment. ${ }^{15}$ In the midst of pandemic, teamwork among healthcare workers become a more important matter to overcome the challenges and to manage the COVID-19 patients. ${ }^{16,17}$

Although the previous studies reported the impact on mental health among healthcare workers, the information on coping with those mental health challenges is still limited. Identifying the preferred and pragmatic coping strategies among the healthcare workers could contribute valuable information in the planning and implementation of effective mental health support interventions. In a pandemic, collaboration and interprofessional teamwork at a large scale are essential especially if it involves the whole world. ${ }^{18}$ Decades of research postulates that teamwork is best achieved in stable conditions where those involved have time to learn to work together. ${ }^{19}$ Peer support and encouragement could be done to improve mental wellness and to reduce stress at the workplace. ${ }^{20}$ On a contrary, team conflict is a contributing factor for workplace stress and psychological burden. ${ }^{21}$ During times of crisis, teams and their ability to function should be tested. Considering the triggers for the psychological impact and possible coping strategies and support (Fig. 1), we aimed to investigate the practical strategies of coping among healthcare workers in various sectors. Therefore, our study aimed to investigate the coping strategies among healthcare workers from different countries and their attitude towards teamwork during the COVID-19 pandemic.

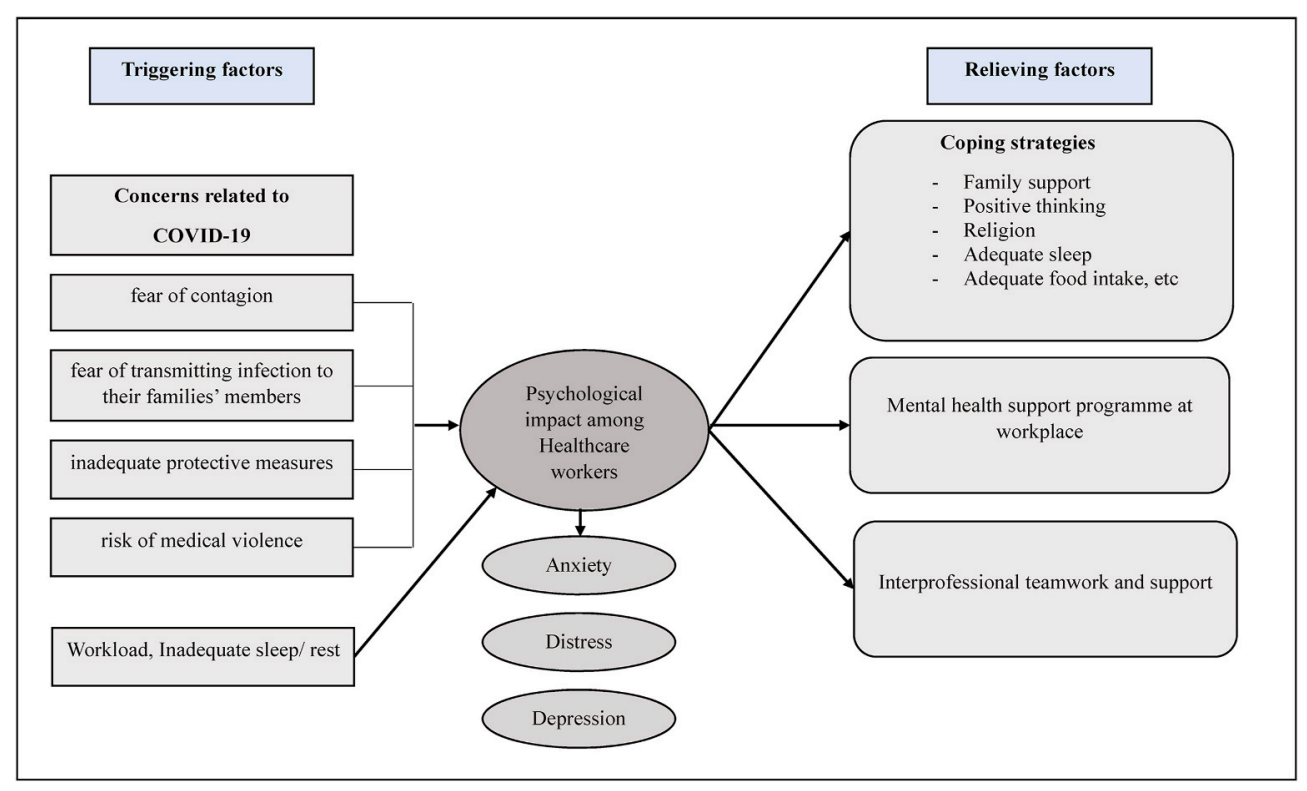

Fig. 1. Triggering and relieving factors for psychological impact among healthcare workers during COVID-19 pandemic. 


\section{Methods}

This cross-sectional study was conducted between April and May 2020. The online, web-based questionnaire was distributed to the different healthcare workers, including doctors, nurses, midwives, laboratory technicians, pharmacists, medical assistants, medical educators, public health practitioners, and medical researchers. We recruited the healthcare workers who are working in both private and public sectors by using the non-random convenience sampling method.

The researchers from 12 countries, including Albania, Egypt, Iraq, Kenya, Mozambique, Myanmar, Palestine, Philippines, South Africa, Tanzania, Uganda, and Zimbabwe collaborated on this study. The COVID-19 situation was at the beginning state of disease spread in those countries at the time of data collection. ${ }^{22}$ The online questionnaire was distributed via email and social media (Fig. 2). All respondents were provided the detailed written information about the research before taking part. Informed consent was obtained from the respondents before the initiation of the online questionnaire. Ethical approval was granted from the Research Ethics Committee from Asia Metropolitan University (AMU), Malaysia, Project Ref No: AMU/MREC/FOM/NF/03/2020.

\subsection{Study instrument}

The respondent's socio-demographic and work-related questions were included in the survey. The coping strategy items were created based on the previous literature and WHO mental health and psychosocial consideration guide. ${ }^{11}$ The question "How do you cope with stress during the COVID-19 pandemic?" was asked to the responses and six leading answers were provided ${ }^{1}$; family support, ${ }^{2}$ peer support, ${ }^{3}$ religion/prayers, ${ }^{4}$ exercise, ${ }^{5}$ positive thinking, ${ }^{6}$ mindfulness/meditation, and $^{7}$ others. Multiple responses were accepted for each respondent. In the "others" option, the respondents were allowed to answer their practical way of coping with the stress during the pandemic.

The attitudes towards teamwork during the pandemic were measured by using five items. The items measure the attitudes towards the positive and negative psychological impact of teamwork, and the effect of teamwork on patients' outcomes. The items were constructed based on the previous literature about interprofessional teamwork, ${ }^{23-26}$ The items are ${ }^{1}$ Interprofessional teamwork and collaboration reduce stress in managing the patients during the pandemic, ${ }^{2} \mathrm{I}$ am willing to discuss patient management with my team members during the pandemic, ${ }^{3}$ Disagreement (or) argument often occur in my team which remains unsolved, ${ }^{4}$ Interprofessional teamwork improved the health outcomes of the patients during the pandemic, and ${ }^{5}$ I am getting psychological support from team members at the workplace during the pandemic. The content validation was carried out by collecting the six expert's opinions on the relevance and representativeness ( 5 clinicians, 1 infectious disease specialist). Descriptive analysis was carried out on the ratings provided by the experts and calculated the Item-Content Validity Index (I-CVI). The I-CVI for items was 0.85 and above and therefore, all the items were included in the questionnaire. ${ }^{27}$ The responses were recorded with a five-point Likert's scale; "strongly disagree", "disagree", "neutral", "agree" and "strongly agree", to indicate the extent to which their agreement on each item at their current workplace.

\subsection{Data analysis}

Descriptive statistic was conducted for the socio-demographic variables, work-related variables, and coping strategies. The preferred coping strategies among different occupation was compared by using Pearson Chi-square test. The scoring was given for the individual item for the attitudes towards teamwork during a pandemic; "strongly disagree $=1$ ", "disagree $=2$ ", "neutral $=3$ ", "agree $=4$ ", and "strongly agree $=5$ ". The reverse scoring was done for the negative item. The mean score for the individual item and the combined score was
Ethical approval was obtained from the Institutional Ethics Committee

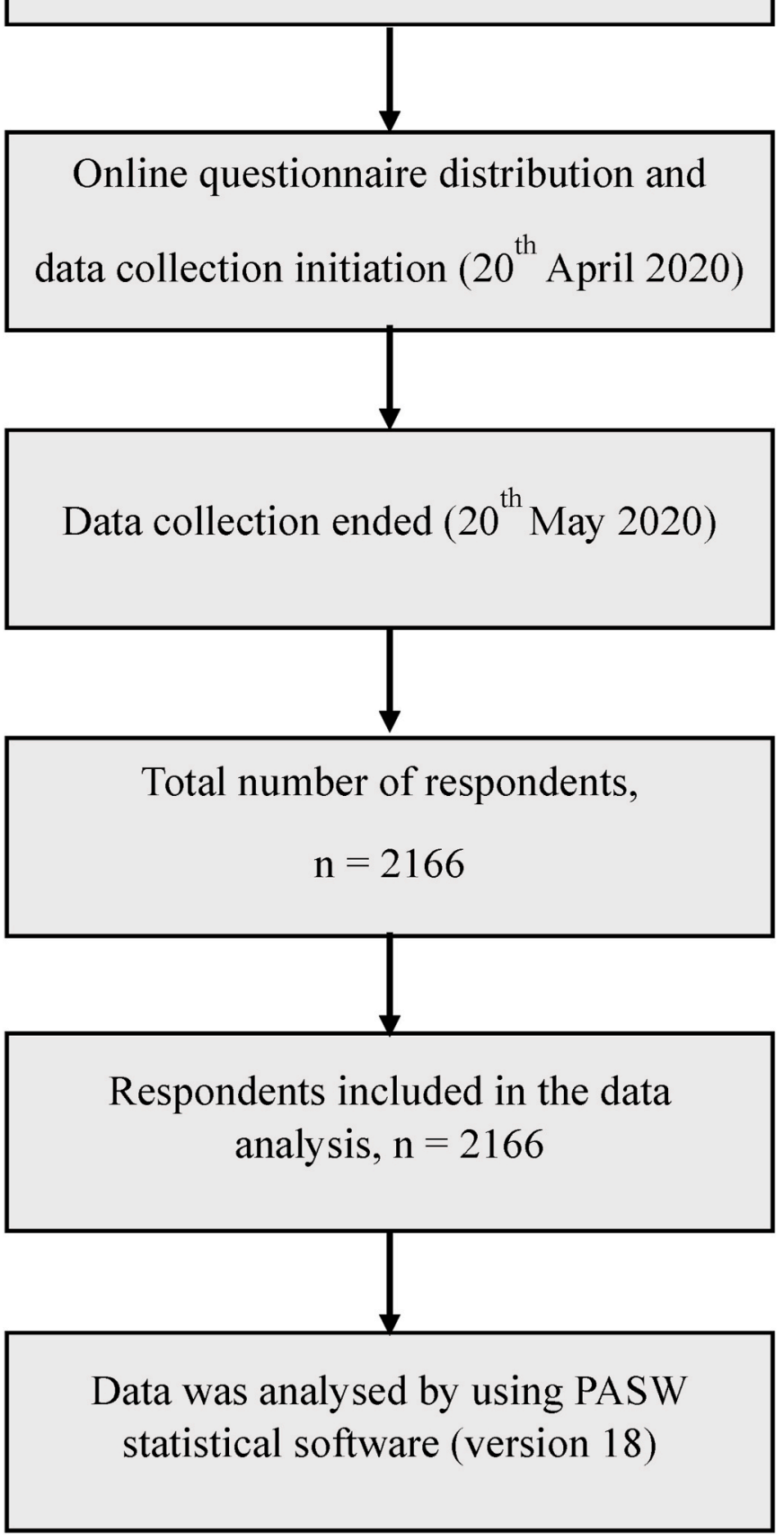

Fig. 2. Data collection and participants flow chart of the study.

computed. General linear model (GLM) analysis was conducted to test the association between the characteristics of respondents and attitudes towards teamwork during the pandemic.

\section{Results}

The geographic distribution of the respondents was shown in Table 1. A total of 2166 respondents from 32 countries responded to the survey, and the majority of them (77\%) were from lower-middle income countries (Table 1, Fig. 3). 
Table 1

Geographic distribution of the participants according to the World Bank country classification on income $(n=2166)$.

\begin{tabular}{|c|c|c|}
\hline $\begin{array}{l}\text { World bank country } \\
\text { classification by income }\end{array}$ & $\begin{array}{l}\text { List of countries and territories of } \\
\text { participants }(n=32)\end{array}$ & n (\%) \\
\hline Low-income countries & $\begin{array}{l}\text { Ethiopia, Mozambique, Nepal, Rwanda, } \\
\text { Syria, Tanzania, Uganda }\end{array}$ & 30 (1.39) \\
\hline $\begin{array}{l}\text { Lower-middle-income } \\
\text { countries }\end{array}$ & $\begin{array}{l}\text { Bangladesh, Egypt, India, Kenya, Lesotho, } \\
\text { Myanmar, Nigeria, Pakistan, Palestine, } \\
\text { Philippines, Zimbabwe, }\end{array}$ & $\begin{array}{l}1674 \\
(77.29)\end{array}$ \\
\hline $\begin{array}{l}\text { Upper-middle-income } \\
\text { countries }\end{array}$ & $\begin{array}{l}\text { Albania, Iraq, Lebanon, South Africa, } \\
\text { Suriname, Thailand }\end{array}$ & $\begin{array}{l}445 \\
(20.54)\end{array}$ \\
\hline High-income countries & $\begin{array}{l}\text { Cyprus, Germany, Greece, Italy, Japan, } \\
\text { Republic of Korea, Sweden, United } \\
\text { Kingdom }\end{array}$ & $17(0.78)$ \\
\hline
\end{tabular}

Table 2 described the socio-demographic characteristics of respondents. Approximately two-thirds (67.2\%) were female respondents. The majority (88.6) were less than 45 years of age. Among them, 36\% were doctors, $24 \%$ were nurses and $40 \%$ worked at other healthcare sectors such as pharmacists, laboratory technicians, public health specialists, medical educators, and healthcare administrators. More than half of the respondents (57.2\%) had working experiences of 6 years and above in their profession (Table 2).

The coping strategies among the doctors, nurses, and other healthcare workers were reported in Table 3 . More than $70 \%$ of the respondents answered that "getting family support" and "positive thinking" were coping methods for them during the COVID-19 pandemic. Approximately half of the respondents worshiped and prayed (58.4\%) and had adequate sleep and food intake (48.2\%). A significant difference in preferred coping methods was observed among doctors, nurses, and other healthcare workers.

The doctors reported a higher preference for 'positive thinking, religious/prayers, exercise, getting peer support, and mindfulness/ meditation methods' compared to the nurses and others. Meanwhile, the nurses reported higher preference on 'satisfaction with job achievement, reading, planning for global responses and new ideas, and other coping strategies including playing games, farming, gardening, participation in voluntary activities, concentrating on work (working all the time), playing sports at home, staying away from fake news, E-learning, learning for career, cooking, writing stories' compared to doctors and other healthcare workers. 'Adequate sleep and food intake, watching television, learning new things, learning the situation' were higher among the other healthcare workers compared to doctors and nurses (Table 3).

The mean score and standard deviation for each item of the respondents' attitude towards interprofessional teamwork were reported in Supplementary Table 1. Four out of five items had more on the agreement responses while taking into account that reverse scoring was carried out for item No. ${ }^{3}$ However, the mean score of the statement "I am getting psychological support from team members at the workplace during pandemic" was only 2.51 (SD 1.31), indicating the disagreement or neutral on that statement (Supplementary Table 1). The Cronbach's alpha of all the items was 0.66 . The skewness of the overall mean score was -0.52 and kurtosis was -0.54 .

Table 4 reported the association between the characteristics of respondents and the mean attitude score towards inter-professional teamwork during the pandemic by using GLM analysis. Significant associations were observed between gender, age, marital status, occupation, working experience, and current workplace (Table 4).

The mean attitude score towards the inter-professional teamwork among females was 0.504 units less than the male healthcare workers (p $<0.01$ ). Meanwhile, the mean score was 1.249 units higher among the age group of 31-45 years compared to the younger age, $<30$ years ( $\mathrm{p}<$ 0.001 ). The single healthcare workers had 1.172 units of higher mean score compared to the married respondents $(\mathrm{p}<0.001)$. Those who are working in the other healthcare sectors had 1.130 units lower mean score compared to the doctors $(\mathrm{p}<0.001)$. Those who had working experience between 2 and 5 years had a lower mean score of 1.074 units compared to those who had $>10$ years' experience $(p=0.005)$. Healthcare workers stationed at the clinics had the highest mean score $(\mathrm{p}=0.002)$, meanwhile, those who are working at the other places had the lowest mean score $(\mathrm{p}<0.001)$ (Table 4$)$.

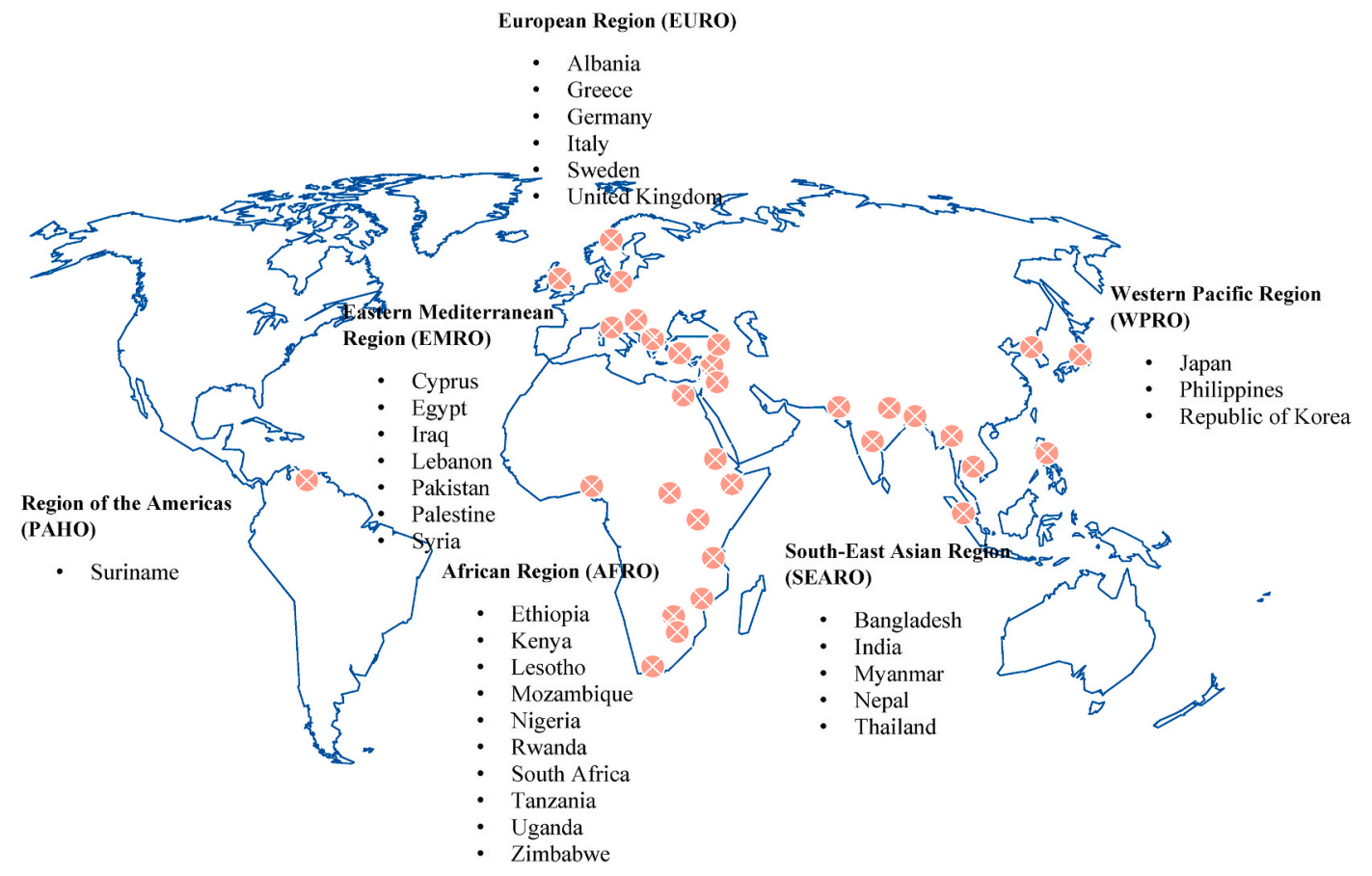

Fig. 3. Geographic distribution of the respondents from 32 countries $(n=2166)$. 
Table 2

Socio-demographic characteristics and occupation of participants $(n=2166)$.

\begin{tabular}{|c|c|}
\hline Characteristics of respondents & $\mathrm{n}(\%)$ \\
\hline \multicolumn{2}{|l|}{ Gender } \\
\hline Male & $710(32.8)$ \\
\hline Female & $1454(67.2)$ \\
\hline \multicolumn{2}{|l|}{ Age } \\
\hline$<30$ years & $1003(46.7)$ \\
\hline $31-45$ years & 900 (41.9) \\
\hline 46 years and above & $244(11.4)$ \\
\hline \multicolumn{2}{|l|}{ Religion } \\
\hline Buddhism & $67(3.1)$ \\
\hline Christian & $711(32.9)$ \\
\hline Islam & 1317 (60.9) \\
\hline Others $^{\mathrm{a}}$ & $36(1.7)$ \\
\hline No religion & $30(1.4)$ \\
\hline \multicolumn{2}{|l|}{ Marital status } \\
\hline Married & $1250(57.8)$ \\
\hline Single & $912(42.2)$ \\
\hline \multicolumn{2}{|l|}{ Occupation } \\
\hline Doctor & $779(36.0)$ \\
\hline Nurse & $520(24.0)$ \\
\hline Others ${ }^{\mathrm{b}}$ & $867(40.0)$ \\
\hline \multicolumn{2}{|l|}{ Work experience } \\
\hline$<2$ years & $384(18.3)$ \\
\hline $2-5$ years & $515(24.5)$ \\
\hline 6-10years & $380(18.1)$ \\
\hline >10years & $822(39.1)$ \\
\hline \multicolumn{2}{|c|}{ Staying with (at the time of COVID-19 pandemic) } \\
\hline Alone & $140(6.5)$ \\
\hline Family & $1887(87.4)$ \\
\hline Friends/colleagues & $133(6.2)$ \\
\hline \multicolumn{2}{|l|}{ Current workplace } \\
\hline Clinics & $373(17.8)$ \\
\hline Hospital & 1004 (47.9) \\
\hline Laboratory & $61(2.9)$ \\
\hline Pharmacy & $80(3.8)$ \\
\hline Others ${ }^{c}$ & $576(27.5)$ \\
\hline
\end{tabular}

a Others included Hinduism and Shinto.

b Others included pharmacists, laboratory technicians, public health specialists, medical educators, and healthcare administrators.

c Others included healthcare institutions, Ministry of Health, NonGovernmental Organizations.

\section{Discussion}

The mental health effects of the COVID-19 pandemic among healthcare workers have been well documented. ${ }^{28}$ Recent studies from all over the globe reported healthcare workers suffering from increased stress to psychological distress, anxiety, depression, insomnia, and other mental health issues during the pandemic. ${ }^{29-31}$ There had even been reports of suicide among these workers due to the physical and psychological burden during that time. ${ }^{32,33}$

Stress, if not managed early and appropriately may result in mental illness. Lack of resources, lack of professional and informal support, being overworked to the point of exhaustion as well as fear of being contaminated and spreading the disease to others were frequently cited as the reasons for the negative mental health effects on healthcare workers during the recent outbreak. ${ }^{32,34}$ Apart from individual causes, conflicts and difficulties during interprofessional collaboration may contribute as sources of stress. ${ }^{35}$ Removal of the source of stress is the most effective remedy for symptom resolution. Nevertheless, this is not always possible. Health services on the verge of collapse due to years of poor funding and management do not miraculously recover but tend to decline further. Hence, implementing good coping strategies and improving teamwork skills are necessary for these workers in order to weather the difficult situation.

\subsection{Coping}

Health professionals in this study coped with their distress during the pandemic using a plethora of techniques ranging from psychological,
Table 3

Coping strategies for mental health burden among healthcare workers ( $\mathrm{n}=$ 2166).

\begin{tabular}{|c|c|c|c|c|c|}
\hline \multirow[t]{2}{*}{ Coping strategies } & \multicolumn{5}{|c|}{ Occupation } \\
\hline & $\begin{array}{l}\text { Doctor (n } \\
=770) n \\
(\%)\end{array}$ & $\begin{array}{l}\text { Nurse (n } \\
=479) n \\
(\%)\end{array}$ & $\begin{array}{l}\text { Others }^{\mathrm{a}}(\mathrm{n} \\
=848) \mathrm{n} \\
(\%)\end{array}$ & $\begin{array}{l}\text { Total (n } \\
=2097) \\
n(\%)\end{array}$ & $\begin{array}{l}\mathrm{p} \\
\text { value }^{\mathrm{b}}\end{array}$ \\
\hline $\begin{array}{l}\text { Getting family } \\
\text { support }\end{array}$ & $\begin{array}{l}580 \\
(74.5)\end{array}$ & $\begin{array}{l}359 \\
(69.0)\end{array}$ & $629(72.5)$ & $\begin{array}{l}1568 \\
(72.4)\end{array}$ & 0.101 \\
\hline Positive thinking & $\begin{array}{l}620 \\
(79.6)\end{array}$ & $\begin{array}{l}362 \\
(69.6)\end{array}$ & $552(63.7)$ & $\begin{array}{l}1534 \\
(70.8)\end{array}$ & $<0.001$ \\
\hline Religious/Prayers & $\begin{array}{l}600 \\
(77.0)\end{array}$ & $\begin{array}{l}245 \\
(47.1)\end{array}$ & $421(48.6)$ & $\begin{array}{l}1266 \\
(58.4)\end{array}$ & $<0.001$ \\
\hline $\begin{array}{l}\text { Adequate sleep } \\
\text { and food intake }\end{array}$ & $\begin{array}{l}385 \\
(49.4)\end{array}$ & $\begin{array}{l}175 \\
(33.7)\end{array}$ & 485 (55.9) & $\begin{array}{l}1045 \\
(48.2)\end{array}$ & $<0.001$ \\
\hline Exercise & $\begin{array}{l}278 \\
(35.7)\end{array}$ & $\begin{array}{l}181 \\
(34.8)\end{array}$ & $240(27.7)$ & $\begin{array}{l}699 \\
(32.3)\end{array}$ & 0.001 \\
\hline $\begin{array}{l}\text { Watching } \\
\text { television }\end{array}$ & $\begin{array}{l}101 \\
(13.0)\end{array}$ & $\begin{array}{l}115 \\
(22.1)\end{array}$ & $380(43.8)$ & $\begin{array}{l}596 \\
(27.5)\end{array}$ & $<0.001$ \\
\hline $\begin{array}{l}\text { Getting peer } \\
\text { support }\end{array}$ & $\begin{array}{l}310 \\
(39.8)\end{array}$ & $\begin{array}{l}170 \\
(32.7)\end{array}$ & $104(12.0)$ & $\begin{array}{l}584 \\
(27.0)\end{array}$ & $<0.001$ \\
\hline $\begin{array}{l}\text { Learning new } \\
\text { things }\end{array}$ & $55(7.1)$ & $\begin{array}{l}58 \\
(11.2)\end{array}$ & $270(31.1)$ & $\begin{array}{l}383 \\
(17.7)\end{array}$ & $<0.001$ \\
\hline $\begin{array}{l}\text { Satisfaction with } \\
\text { job achievement } \\
\text { (weekly plan) }\end{array}$ & $50(6.4)$ & $\begin{array}{l}89 \\
(17.1)\end{array}$ & 119 (13.7) & $\begin{array}{l}258 \\
(11.9)\end{array}$ & $<0.001$ \\
\hline Learn the situation & $92(11.8)$ & $41(8.1)$ & $124(14.3)$ & $\begin{array}{l}258 \\
(11.9)\end{array}$ & 0.002 \\
\hline Reading & $46(5.9)$ & $\begin{array}{l}83 \\
(16.0)\end{array}$ & $113(13.0)$ & $\begin{array}{l}242 \\
(11.2)\end{array}$ & $<0.001$ \\
\hline $\begin{array}{l}\text { Mindfulness/ } \\
\text { Meditation }\end{array}$ & $\begin{array}{l}146 \\
(18.7)\end{array}$ & $30(5.8)$ & $60(6.9)$ & $\begin{array}{l}236 \\
(10.9)\end{array}$ & $<0.001$ \\
\hline $\begin{array}{l}\text { Planning for global } \\
\text { responses and } \\
\text { new ideas }\end{array}$ & $23(3.0)$ & $34(6.5)$ & 39 (4.5) & $96(4.4)$ & 0.009 \\
\hline Use app SAM & $20(2.6)$ & $12(2.3)$ & $18(2.1)$ & $50(2.3)$ & 0.803 \\
\hline Others $^{c}$ & $23(3.0)$ & $\begin{array}{l}112 \\
(21.5)\end{array}$ & $62(7.2)$ & $\begin{array}{l}197 \\
(9.1)\end{array}$ & $<0.001$ \\
\hline
\end{tabular}

Note-those who reported 'Yes' to each coping strategy. Multiple answer allowed.

a Others included pharmacists, laboratory technicians, public health specialists, medical educators, and healthcare administrators.

b Pearson's Chi-square.

c Other coping strategies including playing games, farming, gardening, participation in voluntary activities, concentrating on work (working all the time), playing sports at home, staying away from fake news, E-learning, learning for career, cooking, writing stories.

social, and religious/spiritual approaches. Similar findings have been reported in recent studies. ${ }^{36}$ For example, respondents practiced positive thinking as a psychological technique to overcome stress. This is hardly surprising since the use of positive thinking in stress management has been well and truly documented. Well-documented patients' records are valuable for further management and compliance with documentation is essential in the healthcare sector. ${ }^{37}$

The social relationship helps people to manage their stress by enabling them to listen to and encourage each other, regulate emotion and remain resilient. ${ }^{18}$ In our study, respondents reported drawing support from the family being one of the main methods of reducing stress. Although social distancing may hamper physical interactions, the wide availability of social media and online networking platforms has seen their utilisation during outbreak situations increase manifold. ${ }^{38,39}$ However, social support can be a double-edged sword; it may help to ease stress, but it may also worsen stress because some families might show their worries irrationally. ${ }^{40}$ Positive, encouraging words from family and friends enhances stress reduction, but critical or overprotective comments may be counterproductive.

The use of religious and spiritual approaches such as prayers and attending places of worship was also commonplace among our respondents. Increasingly, this is the case not only in communities with a strong religious background but throughout the globe. ${ }^{41}$ Religion and spirituality may modulate the effect of stress in a variety of ways. Faith 
Table 4

Association between the characteristics of respondents and attitudes towards interprofessional teamwork during pandemic $(n=2166)$.

\begin{tabular}{|c|c|c|c|c|c|}
\hline & \multirow{2}{*}{$\begin{array}{l}\text { Mean } \\
\text { (SD) }\end{array}$} & \multirow[t]{2}{*}{ B } & \multicolumn{2}{|l|}{ 95\% C.I. } & \multirow[t]{2}{*}{$\mathrm{p}$ value } \\
\hline & & & Lower & Upper & \\
\hline Intercept & & 16.458 & 15.216 & 17.701 & $<0.001$ \\
\hline \multicolumn{6}{|l|}{ Gender } \\
\hline Male & $\begin{array}{l}17.255 \\
(3.746)\end{array}$ & Reference & & & \\
\hline Female & $\begin{array}{l}16.209 \\
(4.426)\end{array}$ & -0.504 & -0.883 & -0.124 & 0.009 \\
\hline \multicolumn{6}{|l|}{ Age } \\
\hline$<30$ years & $\begin{array}{l}15.545 \\
(4.265)\end{array}$ & Reference & & & \\
\hline $31-45$ years & $\begin{array}{l}17.619 \\
(4.047)\end{array}$ & 1.249 & 0.611 & 1.888 & $<0.001$ \\
\hline 46 years and above & $\begin{array}{l}16.762 \\
(3.808)\end{array}$ & 0.460 & -0.380 & 1.300 & 0.283 \\
\hline \multicolumn{6}{|l|}{ Religion } \\
\hline Buddhism & $\begin{array}{l}17.209 \\
(3.373)\end{array}$ & Reference & & & \\
\hline Christian & $\begin{array}{l}17.918 \\
(4.262)\end{array}$ & 0.452 & -0.543 & 1.447 & 0.373 \\
\hline Islam & $\begin{array}{l}15.739 \\
(4.086)\end{array}$ & -0.626 & -1.610 & 0.358 & 0.212 \\
\hline Others $^{\mathrm{a}}$ & $\begin{array}{l}18.314 \\
(3.243)\end{array}$ & 1.473 & -0.213 & 3.158 & 0.087 \\
\hline No religion & $\begin{array}{l}16.071 \\
(4.045)\end{array}$ & -0.509 & -2.270 & 1.252 & 0.571 \\
\hline \multicolumn{6}{|l|}{ Marital status } \\
\hline Married & $\begin{array}{l}16.153 \\
(4.606)\end{array}$ & Reference & & & \\
\hline Single & $\begin{array}{l}17.117 \\
(3.608)\end{array}$ & 1.172 & 0.776 & 1.568 & $<0.001$ \\
\hline \multicolumn{6}{|l|}{ Occupation } \\
\hline Doctors & $\begin{array}{l}17.633 \\
(4.257)\end{array}$ & Reference & & & \\
\hline Nurses & $\begin{array}{l}17.103 \\
(3.443)\end{array}$ & 0.210 & -0.271 & 0.692 & 0.392 \\
\hline Others $^{\mathrm{b}}$ & $\begin{array}{l}15.256 \\
(4.304)\end{array}$ & -1.130 & -1.1661 & -0.600 & $<0.001$ \\
\hline \multicolumn{6}{|l|}{ Work experience } \\
\hline >10years & $\begin{array}{l}17.442 \\
(4.301)\end{array}$ & Reference & & & \\
\hline$<2$ years & $\begin{array}{l}16.715 \\
(3.530)\end{array}$ & 0.652 & -0.157 & 1.462 & 0.114 \\
\hline $2-5$ years & $\begin{array}{l}14.478 \\
(4.580)\end{array}$ & -1.074 & -1.828 & -0.320 & 0.005 \\
\hline 6-10years & $\begin{array}{l}17.228 \\
(3.346)\end{array}$ & 0.443 & -0.137 & 1.024 & 0.134 \\
\hline \multicolumn{6}{|l|}{ Current workplace } \\
\hline Hospital & $\begin{array}{l}17.233 \\
(4.071)\end{array}$ & Reference & & & \\
\hline Clinics & $\begin{array}{l}17.312 \\
(3.759)\end{array}$ & 0.803 & 0.294 & 1.312 & 0.002 \\
\hline Laboratory & $\begin{array}{l}16.967 \\
(3.317)\end{array}$ & 0.541 & -0.534 & 1.615 & 0.324 \\
\hline Pharmacy & $\begin{array}{l}16.595 \\
(3.002)\end{array}$ & 0.885 & -0.086 & 1.855 & 0.074 \\
\hline Others $^{c}$ & $\begin{array}{l}14.612 \\
(4.619)\end{array}$ & -0.885 & -1.423 & -0.346 & 0.001 \\
\hline \multicolumn{6}{|l|}{$\begin{array}{l}\text { Having contact } \\
\text { with COVID-19 } \\
\text { patients }\end{array}$} \\
\hline No & $\begin{array}{l}16.110 \\
(4.276)\end{array}$ & Reference & & & \\
\hline Yes & $\begin{array}{l}17.316 \\
(4.076)\end{array}$ & -0.011 & -0.422 & 0.400 & 0.957 \\
\hline
\end{tabular}

Note_ coping strategies- "Yes" response is reference.

a Others included Hinduism and Shinto.

b Others included pharmacists, laboratory technicians, public health specialists, medical educators, and healthcare administrators.

c Others included healthcare institutions, Ministry of Health, NonGovernmental Organizations. in the benevolent God may promote positive thinking and hope. ${ }^{42}$ Prayers and meditation may reduce anxiety and stress through distraction. ${ }^{43,44}$ The actions of the religious community may also reduce stress by fostering close family ties and strong support. ${ }^{45}$

The application of simple lifestyle measures such as adequate sleep and a balanced diet must not be overlooked. This is the last of the main relaxation methods used by the respondents in this study. As any healthcare professional worth, their salt will know that looking after themselves is the first principal of taking care of others. Recent studies also recommend that healthcare workers consume plenty of fruits and vegetables, maintain hydration and limit caffeine intake. ${ }^{34}$ Maladaptive coping such as consuming increased amounts of alcohol, using cigarettes and other substances as well as eating excessively are more harmful in the long term, and hence these practices should be best avoided. ${ }^{45}$

The significant difference between the preferred methods of stress reduction among the different healthcare professionals is certainly intriguing. For example, doctors described preference on the use of positive thinking, exercise, prayers, and meditation, as well as peer support and nurses, favoured involvement in activities such as games, gardening, reading, cooking, and e-learning. On the other hand, other healthcare workers opted to relax by having adequate sleep, a good diet, watching television, and learning about the situation. At present, not much is known about these differences. However, it may be postulated that perhaps doctors feel that to seek help is to show weakness and hence prefer to cope by themselves using the means already mentioned while nurses, who are used to working in teams are more open to utilizing external support. Furthermore, each group of healthcare professional face different set of challenges which may influence on their choice of coping styles. Of course, these are just supposition and hence, further research is required to study this phenomenon in more detail.

\subsection{Teamwork}

The main key to effective teamwork can be simplified as coordination of expertise and communication. ${ }^{19}$ Accomplishing these two traits of teamwork provides an experience that enhances learning, care, and performance. ${ }^{19}$ Respondents in our study agree that interprofessional collaboration and teamwork reduce stress, provided that teams work well together under the pressure of pandemic. They concur that communication is important which enables good management of patients, lessens conflicts, and leads to improved health outcomes for patients. However, respondents felt that psychological support among team members during the pandemic was lacking. This is a serious shortcoming that needs to be addressed. Fortunately, efforts are already underway to remedy this inadequacy. For example, the hospital in Wuhan has set up support teams to provide psychological interventions for healthcare workers. ${ }^{31}$ In time, this practice will spread to other countries and psychological support for medical professionals may be the norm rather than an aberration.

Our study also found that male health professionals, those between the age 31-45 years, single, have been working between 2 and 5 years, employed in the clinic setting, and are not doctors or nurses have a more favourable attitude towards teamwork. The other parameters have not been found to be significant. However, it is not the aim of this study to determine the factors associated with attitude towards teamwork, hence only a brief discourse is possible at this juncture. Perhaps, the negative attitude on interprofessional collaboration among doctors and nurses may have stemmed from their medical and nursing school days where they were trained exclusively among themselves. Hence, early exposure to interprofessional collaboration may be warranted and should be considered in the medical and nursing curricula. ${ }^{35}$

\subsection{Strengths and limitations of the study}

The study attracted involvement from respondents from all over the world. Respondents also spanned the different roles in the health 
profession. The total number of respondents is fairly large. All of these aspects are in favour of the study and its findings can be applied to most communities in the world.

Nevertheless, the use of the convenience sampling method is its main weakness. Convenience sampling may lead to bias. Also, utilisation of online surveys yielded a lower response rate, relative to the population studied. Although there might be different challenges in the private and public healthcare sectors, this study was not able to address these challenges. However, the number of respondents included at the end is large enough to mitigate both the effects bias and lower response rate.

\section{Conclusion and recommendations}

In this study, family support, positive thinking, and religious/prayers were the most preferred strategies for coping with psychological impact among the healthcare workers in the amidst of COVID-19 pandemic. The local healthcare authorities should promote the coping methods and develop an innovative way to encourage practicing among healthcare workers. Although interprofessional teamwork reduces the stress under the pressure of pandemic, psychological support from the team member is lacking and which should be taken lightly. Moreover, mental health support teams should be in place at work to protect and improve the mental wellbeing of healthcare workers.

At the individual level, (i) getting support from family members, (ii) social support, (iii) participating in mindfulness practices could improve personal resilience during the COVID-19 pandemic. ${ }^{46,47}$ At the organization level, (i) creating a positive workplace and teamwork collaboration, (ii) arranging work schedule to enable adequate rest and sleep, (iii) providing rest areas at the workplace for the healthcare workers at long shift, (iv) providing mental health support and counselling, (v) arranging stress management programmes and online resilience training modules could help to improve resilience and coping up mental health challenges among healthcare workers. ${ }^{47-49}$

\section{Funding}

The author(s) received no financial support for the research, and/or publication of this article.

\section{Ethics approval}

Ethical approval was granted from the Research Ethics Committee from Asia Metropolitan University (AMU), Malaysia, Project Ref No: AMU/MREC/FOM/NF/03/2020.

\section{Consent to participate and publication}

Informed consent was obtained from all study respondents.

\section{Availability of data and material}

Data can be made available upon request.

\section{Authors' contributions}

MNNH and RRM conceptualised and planned the project. ALA, TTS, and SM supervised the project. MNNH, RRM, AA, FK, RAE, JMN, HAH, $\mathrm{MH}$ planned and coordinated the study and data collection. MNNH and RRM conducted the statistical analysis. MLNNH and RB drafted the manuscript. TTS and SM led the editing and refinement of the manuscript. All authors contributed to, reviewed and approved the final manuscript.

\section{Declaration of competing interest}

The authors declare no conflict of interest.

\section{Acknowledgement}

We would like to acknowledge 'North Star Alliance' which is a NonGovernmental Organisation providing essential primary healthcare along transport corridors and across borders in Sub-Saharan Africa for their support during the data collection. We also would like to thank the respondents from different healthcare sectors.

\section{Appendix A. Supplementary data}

Supplementary data to this article can be found online at https://doi. org/10.1016/j.cegh.2021.100759.

\section{References}

1 Varshney M, Parel JT, Raizada N, Sarin SK. Initial psychological impact of COVID-19 and its correlates in Indian Community: an online (FEEL-COVID) survey. PloS One. 2020;15(5), e0233874.

2 Dai Y, Hu G, Xiong H, Qiu H, Yuan X. Psychological Impact of the Coronavirus Disease 2019 (COVID-19) Outbreak on Healthcare Workers in China. 2020,

2020.03.03.20030874.

3 Xiang YT, Yang Y, Li W, et al. Timely mental health care for the 2019 novel coronavirus outbreak is urgently needed. Lancet Psychiatr. 2020;7(3):228-229.

4 Nilima N, Kaushik S, Tiwary B, Pandey PK. Psycho-social factors associated with the nationwide lockdown in India during COVID- 19 pandemic. Clin Epidemiol Glob Health. 2021;9:47-52.

5 Lai J, Ma S, Wang Y, et al. Factors associated with mental health outcomes among health care workers exposed to coronavirus disease 2019. JAMA Netw Open. 2020;3 (3), e203976.

6 Bohlken J, Schömig F, Lemke MR, Pumberger M, Riedel-Heller SG. [COVID-19 pandemic: stress experience of healthcare workers - a short current review]. Psychiatr Prax. 2020;47(4):190-197.

7 Pappa S, Ntella V, Giannakas T, Giannakoulis VG, Papoutsi E, Katsaounou P. Prevalence of depression, anxiety, and insomnia among healthcare workers during the COVID-19 pandemic: a systematic review and meta-analysis. Brain Behav Immun. 2020;88:901-907. https://doi.org/10.1016/j.bbi.2020.05.026.

8 Talevi D, Socci V, Carai M, et al. Mental health outcomes of the CoViD-19 pandemic. Riv Psichiatr. 2020;55(3):137-144.

9 Gupta AK, Mehra A, Niraula A, et al. Prevalence of anxiety and depression among the healthcare workers in Nepal during the COVID-19 pandemic. Asian J Psychiatr. 2020; 54:102260.

10 Leão T, Campos-Matos I, Bambra C, Russo G, Perelman J. Welfare states, the Great Recession and health: trends in educational inequalities in self-reported health in 26 European countries. PloS One. 2018;13(2), e0193165.

11 World Health Organization. Mental Health and Psychosocial Considerations during the COVID-19 Outbreak. 2020. Contract No.: WHO/2019-nCoV/MentalHealth/2020.1.

12 Raven J, Wurie H, Witter S. Health workers' experiences of coping with the Ebola epidemic in Sierra Leone's health system: a qualitative study. BMC Health Serv Res. 2018;18(1):251.

13 Munawar K, Choudhry FR. Exploring stress coping strategies of frontline emergency health workers dealing covid-19 in Pakistan: a qualitative inquiry. Am J Infect Contr. 2021;49(3):286-292. https://doi.org/10.1016/j.ajic.2020.06.214.

14 Epstein NE. Multidisciplinary in-hospital teams improve patient outcomes: a review. Surg Neurol Int. 2014;5(Suppl 7):S295-S303.

15 Rafferty AM, Ball J, Aiken LH. Are teamwork and professional autonomy compatible, and do they result in improved hospital care?. 2001;10(suppl 2):ii32-i37.

16 Tannenbaum SI, Traylor AM, Thomas EJ, Salas E. Managing Teamwork in the Face of Pandemic: Evidence-Based Tips. 2020. bmjqs-2020-011447.

17 Cron RQ, Chatham WW. Teamwork, A Novel Concept during an Infectious Pandemic? jrheum; 2020, 200744.

18 Bavel JJV, Baicker K, Boggio PS, et al. Using social and behavioural science to support COVID-19 pandemic response. Nat Hum Behav. 2020;4(5):460-471.

19 Mayo AT. Teamwork in a pandemic: insights from management research. 2020;4(2): 53-56.

20 Mental CDC. Health in the Workplace: Centers for Disease Control and Prevention (CDC); 2019 [Available from: https://www.cdc.gov/workplacehealthpromotion/tools-reso urces/workplace-health/mental-health/index.html.

21 Rajgopal T. Mental well-being at the workplace. Indian J Occup Environ Med. 2010;14 (3):63-65.

22 Who. WHO Coronavirus Disease (COVID-19) Dashboard; 2020 [Available from: https ://covid19.who.int/.

23 Parsell G, Bligh J. The development of a questionnaire to assess the readiness of health care students for interprofessional learning (RIPLS). Med Educ. 1999;33(2):95-100.

24 O'Daniel M, Rosenstein AH. Professional communication and team collaboration. In: Hughes R, ed. Patient Safety and Quality: An Evidence-Based Handbook for Nurses. US. Rockville (MD): Agency for Healthcare Research and Quality (US); 2008.

25 Jerng JS, Huang SF, Liang HW, et al. Workplace interpersonal conflicts among the healthcare workers: retrospective exploration from the institutional incident reporting system of a university-affiliated medical center. PloS One. 2017;12(2), e0171696.

26 London Leadership Academy. Leadership toolkit: team effectiveness questionnaire London, UK [Available from: https://www.londonleadershipacademy.nhs.uk/sites /default/files/Team_effectiveness_diagnostic-LAL1.pdf. 
27 Polit DF, Beck CT, Owen SV. Is the CVI an acceptable indicator of content validity? Appraisal and recommendations. Res Nurs Health. 2007;30(4):459-467.

28 Graham Y, Fox A, Scott J, Johnson M, Hayes C. How a pandemic affects the mental health of the nursing workforce. Nurs Times. 2020;116(8).

29 Zhang SX, Liu J, Jahanshahi AA, Nawaser K, Li J, Alimoradi H. When the Storm Is the Strongest: Healthcare Staff's Health Conditions and Job Satisfaction and Their Associated Predictors during the Epidemic Peak of COVID-19. medRxiv; 2020.

30 Wang S, Wen X, Dong Y, Liu B, Cui M. Psychological Influence of Coronavirus Disease 2019 (COVID-19) Pandemic on the General Public, Medical Workers, and Patients with Mental Disorders and its Countermeasures. 2020. Psychosomatics.

31 Burdorf A, Porru F, Rugulies R. The COVID-19 (Coronavirus) pandemic: consequences for occupational health. Scand J Work Environ Health. 2020;46(3):229-230.

32 Buheji M. Nursing human factor during COVID-19 pandemic. Int J Nurs Sci. 2020;(1): 2020.

33 Dean W. Suicides of Two Health Care Workers Hint at the Covid-19 Mental Health Crisis to Come. STAT News; 2020.

34 Cristina P, Jennifer B, Anabelle B, et al. Recomendaciones nutricionales para el personal de salud y el personal esencial expuesto a la COVID-19 en Latinoamérica. Arch Latinoam Nutr. 2019;69(4).

35 Farhin D. The Relationship between Stress and Teamwork during Interprofessional Collaboration: An Integrative Literature Review. North West University, Boloka institutional repository; 2020.

36 Bahari R, Mohamad Alwi MN, Jahan N, Ahmad MR, Mohd Saiboon I. How do people cope with post traumatic distress after an accident? The role of psychological, social and spiritual coping in Malaysian Muslim patients. Eur J Psychother Counsell Health. 2016;18(4):349-366.

37 Khan MA, Nilima N, Prathibha J, Tiwary B, Singh M. Documentation compliance of in-patient files: a cross sectional study from an east India state. Clin Epidemiol Glob Health. 2020;8:994-997.
38 Brooks SK, Webster RK, Smith LE, et al. The psychological impact of quarantine and how to reduce it: rapid review of the evidence. Lancet. 2020;395(10227):912-920.

39 Chevance A, Gourion D, Hoertel N, et al. [Ensuring mental health care during the SARS-CoV-2 epidemic in France: a narrative review]. Encephale. 2020;46(3S):S3-S13.

40 Ogińska-Bulik N. Social support and negative and positive outcomes of experienced traumatic events in a group of male emergency service workers. Int J Occup Saf Ergon. 2015;21(2):119-127.

41 Abu-Raiya H, Pargament KI. Religious coping among diverse religions: commonalities and divergences. Psychol Relig Spiritual. 2015;7(1).

42 Bahari R, Muzafar ALM. Islamic cognitive restructuring for posttraumatic stress disorder. Malays J Med Health Sci. 2019;15.

43 Bahari R. The islamic psycho-spiritual therapy for posttraumatic stress disorder ( IPSP ): a study of feasibility and effects. Int J Pharmaceut Res. 2020;12(4).

44 Polusny MA, Erbes CR, Thuras P, et al. Mindfulness-based stress reduction for posttraumatic stress disorder among veterans: a randomized clinical trial. J Am Med Assoc. 2015;314(5):456-465.

45 Savitsky B, Findling Y, Ereli A, Hendel T. Anxiety and coping strategies among nursing students during the covid-19 pandemic. Nurse Educ Pract. 2020;46:102809.

46 Callahan K, Christman G, Maltby L. Battling burnout: strategies for promoting physician wellness. Adv Pediatr. 2018;65(1):1-17.

47 Heath C, Sommerfield A, BSv Ungern-Sternberg. Resilience strategies to manage psychological distress among healthcare workers during the COVID-19 pandemic: a narrative review. Anaesthesia. 2020;75(10).

48 Dewey C, Hingle S, Goelz E, Linzer M. Supporting clinicians during the COVID-19 pandemic. Ann Intern Med. 2020;172(11):752-753.

49 Maunder RG, Lancee WJ, Mae R, et al. Computer-assisted resilience training to prepare healthcare workers for pandemic influenza: a randomized trial of the optimal dose of training. BMC Health Serv Res. 2010;10:72. 